\title{
PRAÇA DA BANDEIRA EM PRESIDENTE PRUDENTE-SP - DIRETRIZES DE REQUALIFICAÇÃO
}

\author{
Lycia Regina Meira, Yeda Ruiz Maria, Sibila Corral de Arêa Leão Honda \\ Universidade do Oeste Paulista - UNOESTE, Curso de Arquitetura e Urbanismo, Presidente Prudente, SP. E-mail: \\ sibila@unoeste.br
}

\section{RESUMO}

O espaço público é o lugar de representação e de expressão coletiva da sociedade, sendo o lugar de socialização. Ou seja, os principais atributos de um espaço público são os relacionados com a vida e com o convívio públicos. Os espaços verdes e praças são primordiais, vistos como um papel estruturador dos espaços públicos, auxiliando na estrutura das cidades. Ao mesmo tempo, cada cidade é caracteristicamente singular e sofre alterações específicas no tempo. Presidente Prudente, cidade do interior paulista, tem sofrido modificações morfológicas significativas. No início da década de 1970 foi iniciada construção de viaduto que interferiu severamente em duas praças urbanas, degradando-as. Assim, este artigo busca discutir questões relativas a esse processo e a busca por requalificação do espaço urbano. A metodologia está baseada em aprofundamento teórico e levantamento in locu, possibilitando elaboração de diretrizes projetuais.

Palavras-chave: Espaço público, Requalificação urbana, Praça, Barreira urbana.

\section{PRAÇA DA BANDEIRA IN PRESIDENTE PRUDENTE-SP - GUIDELINES FOR REQUALIFICATION}

\begin{abstract}
The public space is the place of representation and collective expression of society, it is the place of socialization. So, the key attributes of a public space are related to the life and the public interaction. Green spaces and squares are fundamental, seen as a structuring role of public spaces, helping to structure of cities. At the same time, each city is unique and has specific diferences in the time. Presidente Prudente, in São Paulo State, has had significant morfological changes. In the early years of 1970's, new viaduct construction began, and it interferd in two squares in the city, degrading them. So, this paper seeks to discuss aspects related to degradation process and the target of requallification in urban space. Metodology was based on theoretical review and analysis in locu, enabling development of projective guidelines.
\end{abstract}

Keywords: Urban space, Urban requalification, Square, Urban barrier. 


\section{INTRODUÇÃO}

O espaço público é o lugar de representação e de expressão coletiva da sociedade pela filosofia política; é o lugar, por excelência, da socialização. Os principais atributos de um espaço público são aqueles relacionados com a vida pública, com urbanidade, possibilitando diversidade de situações e pessoas, propiciando circulação urbana, socialização e diversificação cultural por meio do convívio público, sendo importantes elementos na estrutura das cidades; não devendo ser negligenciados (BORJA, 2003; LEITE, 2011).

Para Del Rio (1990) a importância dos espaços públicos acontece pelas relações que estes guardam com o contexto urbano e com as atividades sociais neles desempenhadas e por eles facilitadas e não pela quantidade de espaços livres de uma cidade.

Cada cidade é caracteristicamente singular, oferece uma essência diferenciada, centraliza uma série de possibilidades que criam um grande poder de sedução individual. Com isso os espaços verdes e/ou praças são primordiais, vistos como um papel estruturador dos espaços públicos e de sociabilização aos indivíduos.

Presidente Prudente é uma cidade localizada no oeste do estado de São Paulo, e assim, como toda cidade, sofre mudanças no decorrer do tempo. Essa cidade, foco da pesquisa que embasa este artigo, teve seu início em 1917 com a abertura do primeiro loteamento (Vila Goulart). Dois anos depois, quando da inauguração da estação ferroviária, outro loteamento foi aberto (Vila Marcondes), no lado oposto à estação.

Área entre a Vila Goulart e a linha férrea foi tornada praça em 1925 - a Praça da Bandeira, um espaço público para o convívio e lazer de sua população. Era caracterizada como espaço de espera por ser o local onde os passageiros da linha férrea aguardavam as charretes. Era o principal local de passeio e namoro da cidade de então (SANTOS, 2001, apud BISPO, 2011).

Mas devido à expansão territorial e ao aumento populacional mudanças estruturais foram necessárias. Foi iniciada a construído de um viaduto - Tannel Abbud - em 1970, que seria um símbolo do progresso. Visava-se integrar as Vilas Goulart e Vila Marcondes, ultrapassando a barreira gerada pela linha férrea.

No entanto ele trouxe sérias consequências que mudaram o desenho urbano da área, e as duas praças - da Bandeira e Nossa Senhora Aparecida, antes interligadas, foram separadas e cada uma seguiu um rumo diferente (BOSCOLI; LANZETTA; OTA, 2013).

A Praça da Bandeira, fechada no lado leste, teve seu uso completamente alterado, tendo perdido seus atrativos, tornando-se um local vazio. Esse cenário somente foi alterado por causa da 
transferência dos vendedores ambulantes, antes situados em diversos pontos do centro da cidade, para um espaço na praça. Atualmente é conhecida como Camelódromo.

A Praça Nossa Senhora Aparecida, localizada na Vila Marcondes é elemento importante do desenvolvimento desse bairro (BISPO, 2011). A igreja edificada ali - Paróquia Nossa Senhora Aparecida - foi fundada em 1940. Aos poucos, devido à construção do viaduto, a praça foi sendo descaracterizada. O movimento atual na praça ocorre devido à igreja, não havendo atrativos para chamar a população a utilizá-la. Muitos moradores de rua se abrigam sob o viaduto na praça.

Além de ter causado danos às duas áreas urbanas - praças, a presença do viaduto em concreto armado transgrediu a beleza eminente do lugar, modificando sua identidade.

A partir desse contexto, este artigo objetiva apresentar conceitos urbanísticos e discutir proposta para gerar nova identidade ao lugar, recuperando o sentimento de posse de lugar por seus usuários. A metodologia utilizada está apoiada em estudo qualitativo, por meio de embasamento teórico e levantamentos de campo.

\section{REQUALIFICAÇÃO URBANA}

A requalificação urbana é um instrumento para intervenções públicas na melhoria dos espaços degradados, buscando-se dar condições para novos usos coletivos de socialização e lazer. Constitui-se como processo social e político de intervenção no território, essencial para a qualidade de vida urbana, por meio de uma maior equidade de formas de produção de um acentuado equilíbrio no uso de ocupação dos espaços e na própria capacidade criativa de inovação dos agentes envolvidos no processo (MOREIRA, 2007).

Para Gondim (2001) a requalificação de locais importantes para a história da cidade é uma tentativa de imortalizar a importância simbólica de um espaço que poderia se perder nas gerações futuras. Moreira (2007) pontua ainda que a requalificação urbana procura reintroduzir as qualidades urbanas, as acessibilidades e a centralidade de uma determinada área, provocando a sua mudança ao nível paisagístico, cultural, social e econômico.

Assim sendo poderia ser considerada como o principal instrumento para a melhoria das condições de vida das populações, promovendo a construção e recuperação de equipamentos e infraestrutura, e a valorização do espaço público com medidas de dinamização social e econômica.

A partir desses conceitos, é possível apoiar a ideia de que é fundamental uma intervenção focada na requalificação no entorno do viaduto Tannel Abbud em Presidente Prudente. 


\section{ESPAÇOS PÚBLICOS}

O espaço público não é meramente o espaço vazio entre edifícios e ruas, nem um espaço vazio considerado público por razões exclusivamente jurídicas. É mais do que isso, é um espaço multifuncional que serve de palco à sociedade; é um espaço físico, simbólico e político onde as relações sociais se estabelecem (BORJA, 2011).

Borja (2011) afirma que contar a história do espaço público é contar a história da própria cidade, e que a qualidade da cidade poderá ser avaliada através do seu espaço público, pois indica a qualidade de vida dos cidadãos e o seu grau de cidadania.

Segundo Machado (2012), para se ter um espaço público funcional e transitável é necessário que haja uma certa qualidade por meio de seus pontos de ônibus, telefones públicos, bancos, luminárias, postes, banca de jornal e vegetações. Nesta vertente Cunha (2003) reconhece o espaço público como áreas verdes de lazer e de uso público, as quais devem ser consideradas como promotores de sustentabilidade urbana, conferindo a qualidade de vida e desempenhando as funções ecológicas, simbólicas e recreativas no ambiente urbano.

Ao observar um espaço público, deve-se considerar de um lado sua configuração física e, de outo, o tipo de práticas e dinâmicas sociais que aí se desenvolvem. Ele passa então a ser analisado como um conjunto indissociável das formas com as práticas e dinâmicas sociais (GOMES, 2002).

Portanto se entende que as qualidades dos espaços públicos se diferenciam de acordo com o setor e/ou região que se esta inserida, ou seja, de acordo com os padrões sócio econômicos. Neste sentido Magalhães (2005) pontua que quando esses espaços se tornam ociosos exercem um paradoxal poder de presença no ambiente urbano, pelo seu potencial em influir na perda da vitalidade urbana e, ao mesmo tempo, constituírem os espaços potenciais para a transformação da condição atual.

Mesmo diante da Lei Federal 6.766/1979, que implementou o controle do uso, ocupação e parcelamento do solo urbano, atribuindo a responsabilidade de planejamento e gestão da área da cidade à esfera municipal, nota-se as prefeituras negligenciaram distribuição e as formas de ocupação dos espaços públicos, acarretando cada vez mais em espaços ociosos a mercê dos cuidados da própria comunidade.

O espaço público de transição abaixo do viaduto, objeto de estudo em discussão neste artigo, apresenta atualmente grande desvio de funcionalidade e degradação, além da grande perda da memória histórica da formação da cidade. 


\section{DIRETRIZES DE INTERVENÇÃO}

Verifica-se a grande necessidade de intervenção na área analisada, buscando-se o resgate de identidade de lugar, no qual a população poderia assumir como espaço público. São duas praças separadas e degradadas pela construção do viaduto Tannel Abud (figura 1).

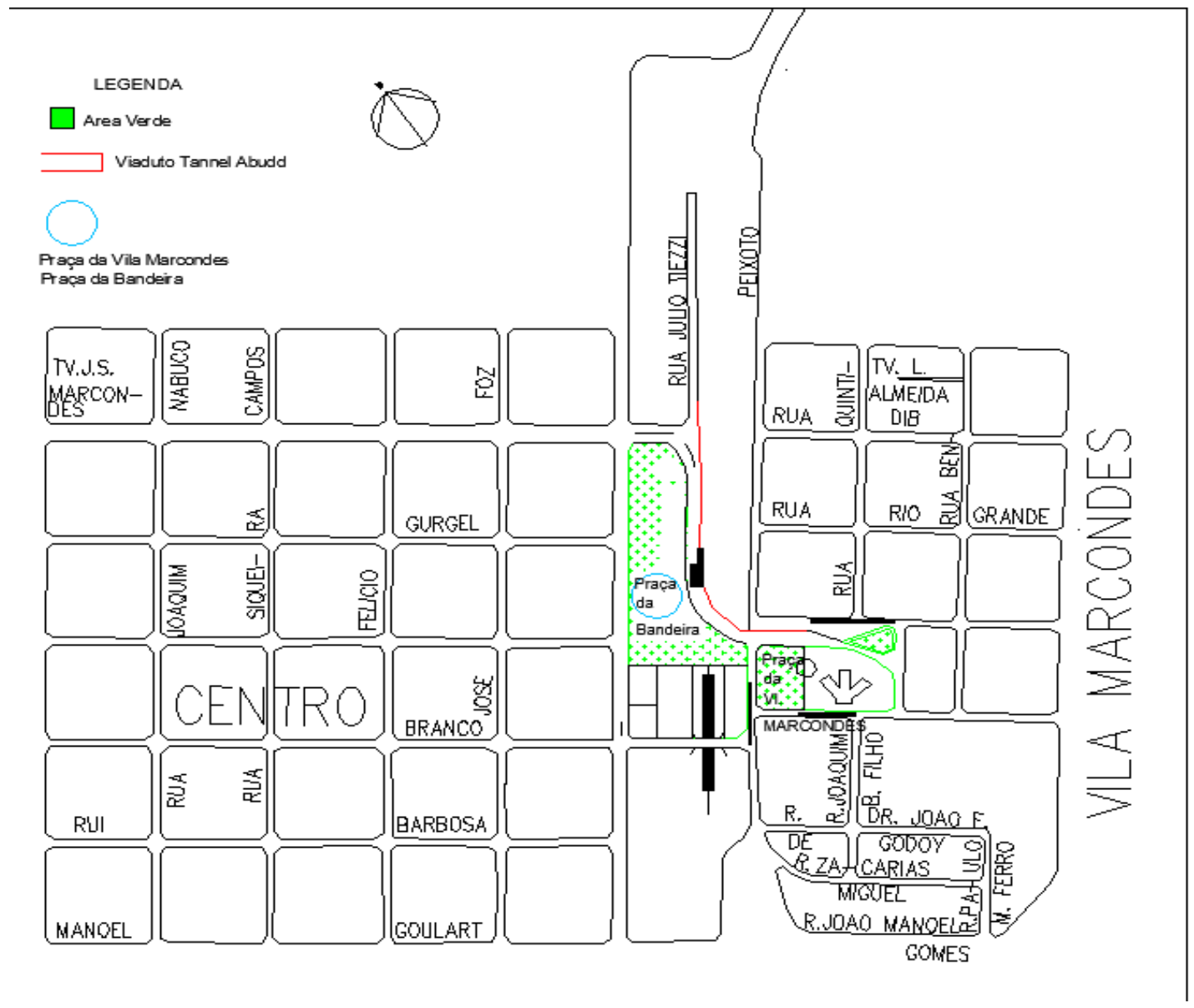

Figura 1. Identificação da área (Fonte: autora, 2015)

A retirada do viaduto, desbloqueando a paisagem, seria interessante, embora poderia vir a causar outros problemas de fluxo e trânsito. Dessa forma, opta-se pela manutenção desse elemento bruto.

A reintegração das duas praças é importante, criando-se um marco urbano que possibilitaria a atração da população para a área. Ao mesmo tempo, a prioridade ao pedestre é fundamental. No entanto, devido à existência da linha férrea, não é possível a integração em nível dos dois lados.

Várias alternativas de integração foram analisadas, e passarelas aéreas ultrapassando a barreira da estrada de ferro mostram-se como a melhor opção. Atualmente há passagem subterrânea, que não pode ficar aberta todo o período da noite por riscos relativos à 
criminalidade. Elevando-se o caminho e atraindo os olhares da população, esta participaria da segurança do local, reduzindo problemas nesse setor.

Se a população for atraída pela estética de novo marco integrando duas áreas urbanas importantes, o uso desses espaços retornaria. Um elemento, que pudesse ser considerado passagem e mirante na cidade para a própria cidade, atrairia usos em diversos momentos do dia e da noite.

Importante destacar que intervenções pontuais muitas vezes apresentam resultados mais adequados no enfrentamento de problemas urbanos. Assim sendo, como diretriz de intervenção para a requalificação desses espaços, foca-se em entregar para uso coletivo o espaço público integrador.

\section{CONSIDERAÇÕES FINAIS}

Neste artigo, buscou-se conceituar aspectos urbanos apoiando a necessidade de intervenção pontual na cidade de Presidente Prudente, interior do Estado de São Paulo. Trata-se de local de grande relevância histórica e social na cidade.

A busca por requalificar espaços públicos é de grande importância para sua população. Ao mesmo tempo, a redução de gastos com projetos mirabolantes é crucial, assim como a atração positiva e constante de usuários torna o projeto suficiente para seu fim.

Verifica-se dessa forma, que é possível, por meio de um elemento construído, devolver à sociedade espaços que outro elemento construído sequestrou.

\section{REFERENCIAS}

BISPO, T.M.S. As Praças Centrais de Presidente Prudente-SP: avaliação do caráter como subsídio para intervenções projetuais. Presidente Prudente: UNESP, 2011. (Trabalho de Conclusão de Curso).

BOSCOLI, M.A.B.; LANZETTA, G.B.; OTA, L.M. Avaliação pós-ocupacional do camelódromo/Praça da Bandeira na cidade de Presidente Prudente - SP. In: Colloquium Humanarum, vol. 10, n. Especial, $\quad 2013.269-276, \quad$ Disponível em: http://www.unoeste.br/site/enepe/2013/suplementos/area/Humanarum/Arquitetura\%20Urbanis mo/AVALIA\%C3\%87\%C3\%83P\%20P\%C3\%93SOCUPACIONAL\%20DO\%20CAMEL\%C3\%93DROMO\%20PRA\%C3\%87A\%20DA\%20BANDEIRA\%20NA \%20CIDADE\%20DE\%20PRESIDENTE\%20PRUDENTE-SP.pdf.

BORJA, J. La ciudad conquistada. Madrid: Alianza Editorail, 2003.

DEL RIO, V. Introdução ao desenho urbano no processo de planejamento. São Paulo: PINI, 1990. 
GOMES, P.C.C. A condição urbana: ensaios de geopolítica da cidade. Rio de Janeiro: Bertrand Brasil, 2002.

GONDIM, L.M.P. A construção social da memória na moderna Fortaleza. In: AGUIAR, O.A.; BATISTA, J.E.; PINHEIRO, J. (Orgs.). Olhares contemporâneos: cenas do mundo em discussão na u A partir desses conceitos, é possível apoiar a ideia de que é fundamental uma intervenção focada na requalificação no entorno do viaduto Tannel Abbud em Presidente Prudente.niversidade. Fortaleza: Edições Demócrito Rocha, 2001.

LEITE, M.A.F.P. Um sistema de espaços livres para São Paulo. In: Estudos Avançados, v. 25, n. 71, 2011. Disponível em: http://www.scielo.br/scielo.php?script=sci_arttext\&pid=S010340142011000100011.

MOREIRA, G. Requalificação Urbana - Alguns Conceitos Básicos. In: Artitextos, no 5, pp.117-129, 2007. Disponível em: http://www.repository.utl.pt/handle/10400.5/1802? mode=full. 